\title{
Modulating Photoelectrochemical Water-Splitting Activity by Charge-Storage Capacity of Electrocatalysts
}

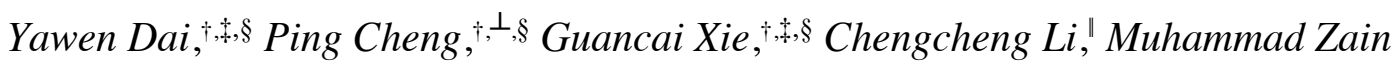 \\ Akram ${ }^{\dagger,}$ Beidou Guo,${ }^{\dagger,}$ Rajender Boddula,${ }^{\dagger}$ Xinghua Shi $,{ }^{\dagger,}, *$ Jinlong Gong $,{ }^{\|}, *$ and \\ Jian Ru Gong ${ }^{\dagger, *}$
}

Chinese Academy of Sciences (CAS) Center for Excellence in Nanoscience, CAS Key Laboratory of Nanosystem and Hierarchy Fabrication, National Center for Nanoscience and Technology, Beijing 100190, China

University of Chinese Academy of Sciences, Beijing 100049, China

${ }^{\perp}$ College of Science, University of Shanghai for Science and Technology, Shanghai 200093, China

'Tianjin University, Tianjin 300072, China

\footnotetext{
* Corresponding author: gongjr@nanoctr.cn (J.R.G.); jlgong@tju.edu.cn (J.G.); shixh@nanoctr.cn (X.S.)

$\S$ These authors contributed equally.
} 


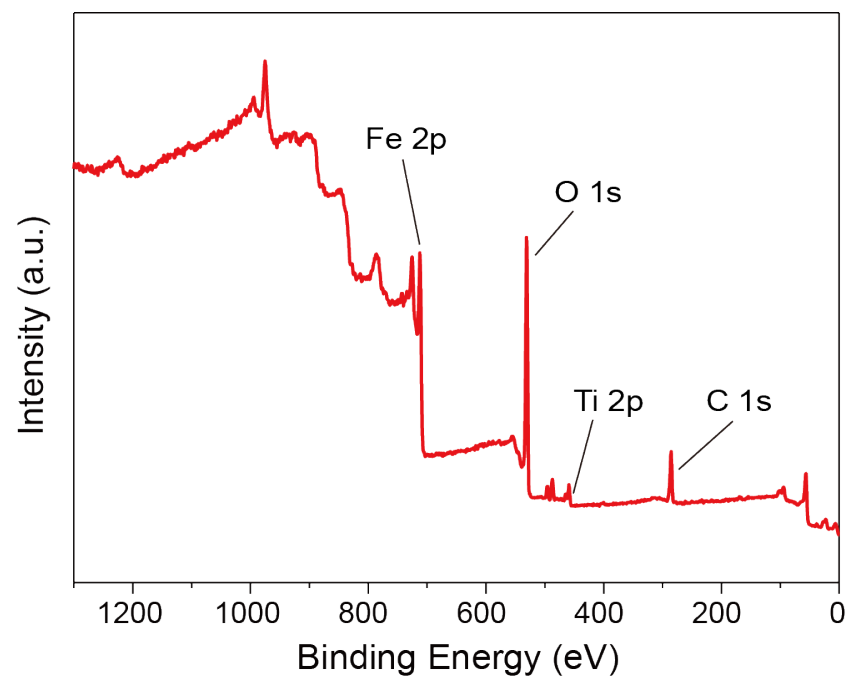

Figure S1. XPS survey spectrum of the $\alpha-\mathrm{Fe}_{2} \mathrm{O}_{3}$ photoanode. 


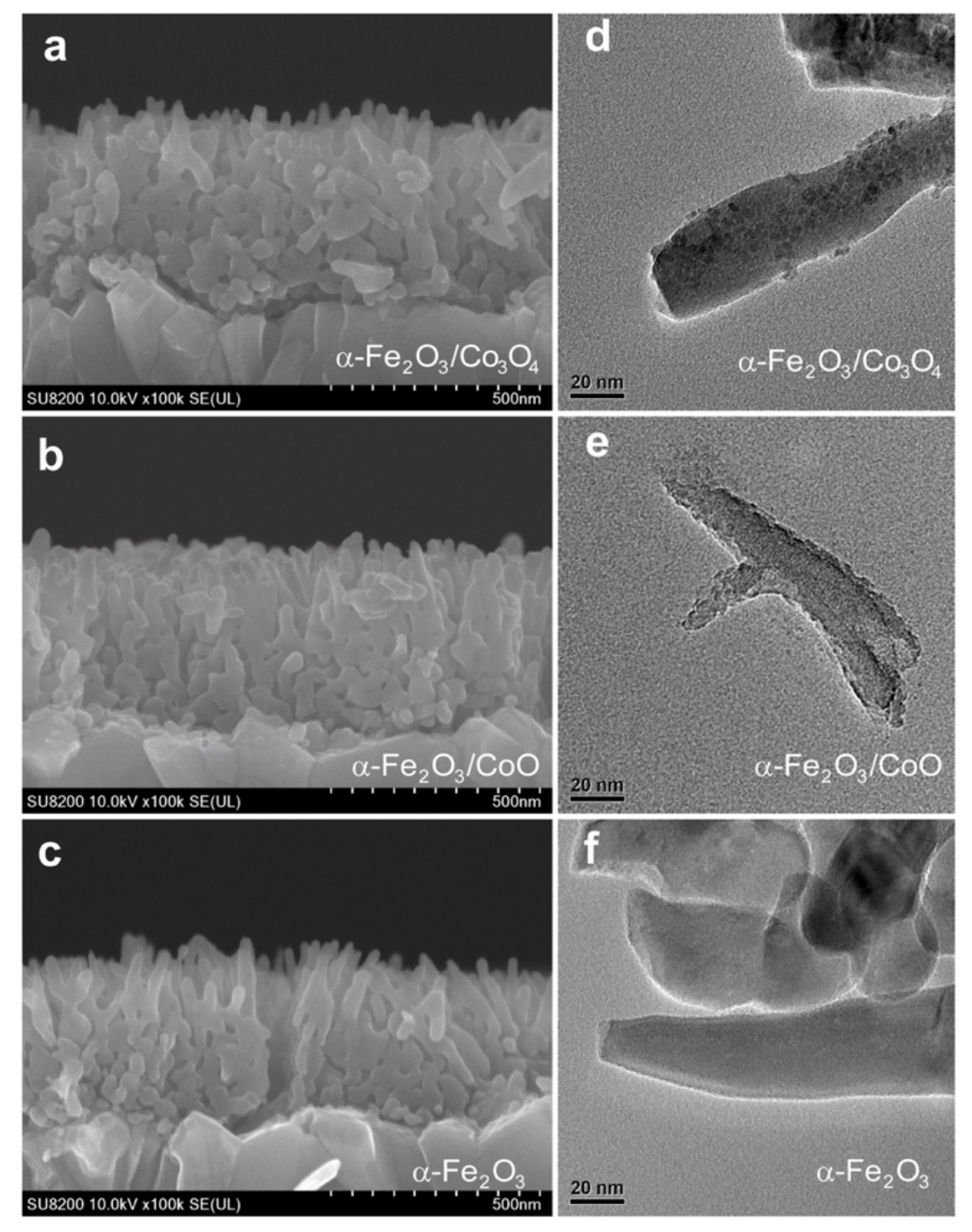

Figure S2. (a-c) Cross-sectional SEM and (d-f) TEM images of $\alpha-\mathrm{Fe}_{2} \mathrm{O}_{3} / \mathrm{Co}_{3} \mathrm{O}_{4}, \alpha-\mathrm{Fe}_{2} \mathrm{O}_{3} / \mathrm{CoO}$, and $\alpha-\mathrm{Fe}_{2} \mathrm{O}_{3}$.

Since both $\mathrm{Co}_{3} \mathrm{O}_{4}$ and $\mathrm{CoO}$ nanoparticles are spin coated on $\alpha-\mathrm{Fe}_{2} \mathrm{O}_{3}$ with irregularly attached interfaces, no well-lattice-matched interfaces can be obtained regardless of the lattice constants. Therefore, the degree of latticemismatch of the $\alpha-\mathrm{Fe}_{2} \mathrm{O}_{3}-\mathrm{Co}_{3} \mathrm{O}_{4}$ and the $\alpha-\mathrm{Fe}_{2} \mathrm{O}_{3}-\mathrm{CoO}$ interfaces can be regarded similar, and thus the interface defects should not be the determinant reason for the PEC OER activity difference. 

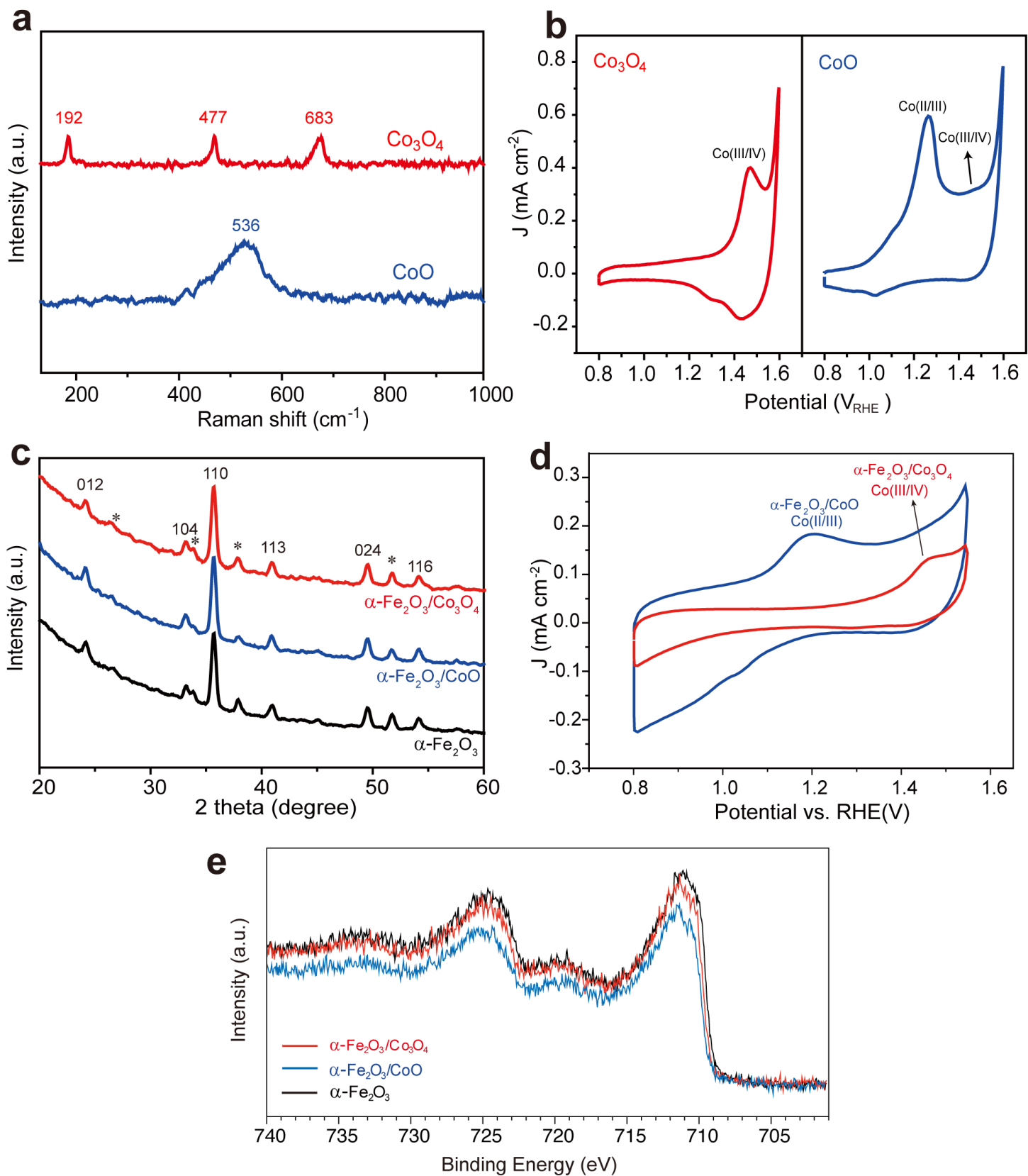

Figure S3. (a) Raman spectra and (b) cyclic voltammetry plots of $\mathrm{Co}_{3} \mathrm{O}_{4}$ and $\mathrm{CoO}$ coated FTO. (c) XRD patterns of $\alpha-\mathrm{Fe}_{2} \mathrm{O}_{3} / \mathrm{Co}_{3} \mathrm{O}_{4}, \alpha-\mathrm{Fe}_{2} \mathrm{O}_{3} / \mathrm{CoO}$, and $\alpha-\mathrm{Fe}_{2} \mathrm{O}_{3}$. *labels $\mathrm{SnO}_{2}$. (d) Dark CV curves of $\alpha-\mathrm{Fe}_{2} \mathrm{O}_{3} / \mathrm{Co}_{3} \mathrm{O}_{4}$ and $\alpha-\mathrm{Fe}_{2} \mathrm{O}_{3} / \mathrm{CoO}$. (e) XPS Fe $2 p$ spectra of $\alpha-\mathrm{Fe}_{2} \mathrm{O}_{3} / \mathrm{Co}_{3} \mathrm{O}_{4}, \alpha-\mathrm{Fe}_{2} \mathrm{O}_{3} / \mathrm{CoO}$, and $\alpha-$ $\mathrm{Fe}_{2} \mathrm{O}_{3}$.

In the Raman spectra (Figure S3a), the single broad peak at $536 \mathrm{~cm}^{-1}$ is assigned to rock salt $\mathrm{CoO}$, while the relatively sharp peaks located at 192, 477, and $683 \mathrm{~cm}^{-1}$ are assigned to spinel $\mathrm{Co}_{3} \mathrm{O}_{4} \cdot{ }^{1}$ The oxidation peaks in $\mathrm{CV}$ plots (Figure $\mathrm{S} 3 \mathrm{~b}$ ) at $1.47 \mathrm{~V}_{\mathrm{RHE}}$ for $\mathrm{Co}_{3} \mathrm{O}_{4}$ and $1.26 \mathrm{~V}$ RHE for $\mathrm{CoO}$ are assigned to the Co (III)/Co (IV) and Co (II)/Co (III) couples, respectively, indicating the dominant valence states of $\mathrm{Co}$ (III) in $\mathrm{Co}_{3} \mathrm{O}_{4}$ and $\mathrm{Co}$ (II) in $\mathrm{CoO} .{ }^{2-3}$ The $\mathrm{CV}$ curves 
are used to demonstrate the original chemical states in the two catalysts instead of detecting OER intermediates. The Co (III)/Co (IV) oxidation peak in $\mathrm{CoO}$ is weak because of the original chemical state of Co (II), which is a commonly observed phenomenon as in other reports, ${ }^{2,4}$ but it also reaches Co (IV) when catalysing OER as demonstrated by the in-situ characterization by other researchers. ${ }^{4}$

We have also presented CV diagrams (Figure S3d) and XPS Fe 2p spectra (Figure S3e) of $\alpha-\mathrm{Fe}_{2} \mathrm{O}_{3} / \mathrm{Co}_{3} \mathrm{O}_{4}$ and the $\alpha-\mathrm{Fe}_{2} \mathrm{O}_{3} / \mathrm{CoO}$. After the deposition of electrocatalysts, feature redox peaks of $\mathrm{Co}(\mathrm{II} / \mathrm{III})$ in $\alpha-\mathrm{Fe}_{2} \mathrm{O}_{3} / \mathrm{CoO}$ and $\mathrm{Co}(\mathrm{III} / \mathrm{IV})$ in $\alpha-\mathrm{Fe}_{2} \mathrm{O}_{3} / \mathrm{Co}_{3} \mathrm{O}_{4}$ are both observed in their corresponding $\mathrm{CV}$ diagrams (Figure S3d), suggesting the decent coverage of the electrocatalysts on the surface of the nano-hematite. Besides, the XPS Fe $2 p$ intensity decreases compared to that of bare hematite (Figure S3e), indicating the successful deposition of the electrocatalysts. These results suggest the interface between hematite and electrocatalyst should play important roles in their PEC activity although the distribution of electrocatalysts on the hematite is not very uniform. 

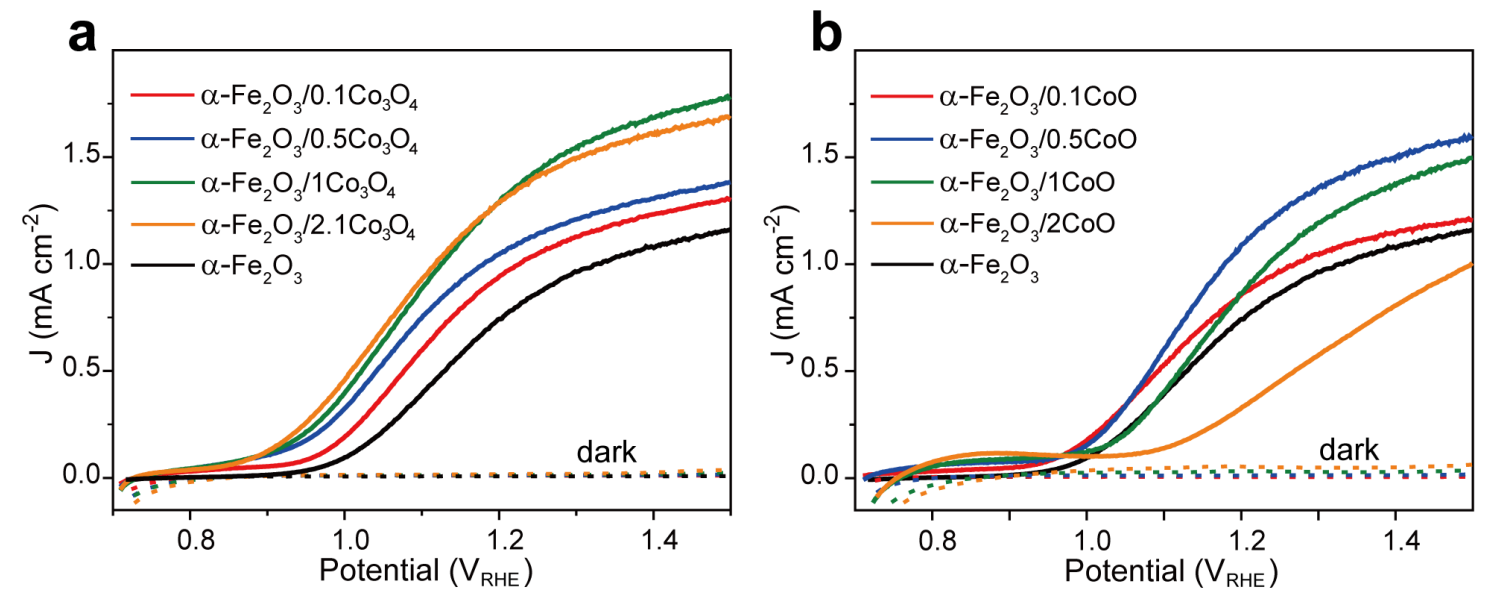

Figure S4. Photocurrent densities of $\alpha-\mathrm{Fe}_{2} \mathrm{O}_{3}$ coated by (a) $\mathrm{Co}_{3} \mathrm{O}_{4}$ and (b) $\mathrm{CoO}$ with different loading amount of the ECs. $\alpha-\mathrm{Fe}_{2} \mathrm{O}_{3} / x$ EC indicates the $\alpha-\mathrm{Fe}_{2} \mathrm{O}_{3}$ spin coated by $x \mathrm{mg} \mathrm{mL}^{-1} \mathrm{EC}$ dispersion. Dashed lines represent the corresponding dark current densities.

The onset potentials of all the $\mathrm{Co}_{3} \mathrm{O}_{4}$ coated $\alpha-\mathrm{Fe}_{2} \mathrm{O}_{3}$ photoandes are more cathodic compared to that of the bare one, and increasing the $\mathrm{Co}_{3} \mathrm{O}_{4}$ loading amount leads to increasingly more cathodically shifted onset potentials. $\alpha$ $\mathrm{Fe}_{2} \mathrm{O}_{3} / 0.1 \mathrm{CoO}$ shows a little more cathodic onset potential than the bare $\alpha$ $\mathrm{Fe}_{2} \mathrm{O}_{3}$, whereas increasing the $\mathrm{CoO}$ loading amount gradually leads to anodically shifted onset potentials. In order to highlight the opposite effect of $\mathrm{Co}_{3} \mathrm{O}_{4}$ and $\mathrm{CoO}, \alpha-\mathrm{Fe}_{2} \mathrm{O}_{3}$ photoanodes coated by $2.1 \mathrm{mg} \mathrm{mL}^{-1} \mathrm{Co}_{3} \mathrm{O}_{4}$ and $2 \mathrm{mg} \mathrm{mL}^{-1} \mathrm{CoO}$ dispersion (both contain $1.5 \mathrm{mg} \mathrm{mL}^{-1}$ Co element) are chosen as the model samples for further in-depth investigation.

Additionally, it can be noticed that a small loading amount of $0.5 \mathrm{mg} \mathrm{mL}^{-1}$ $\mathrm{CoO}$ is also working decently, which is due to its relatively low hole storage capacity thus inducing relatively low interfacial recombination. Therefore, the methods of tuning ECs' hole storage capacity include tuning the loading amount, valence states as explained in the main text, or elemental constituents as indicated by the experiments from Hamann et al. ${ }^{5}$ Regardless of the tuning method used, we should be aware that in essence it is the ECs' hole storage capacity that plays a key role in balancing the competition between interfacial charge transfer and recombination, thus dominating the PEC OER activity of an EC modified photoanode. 

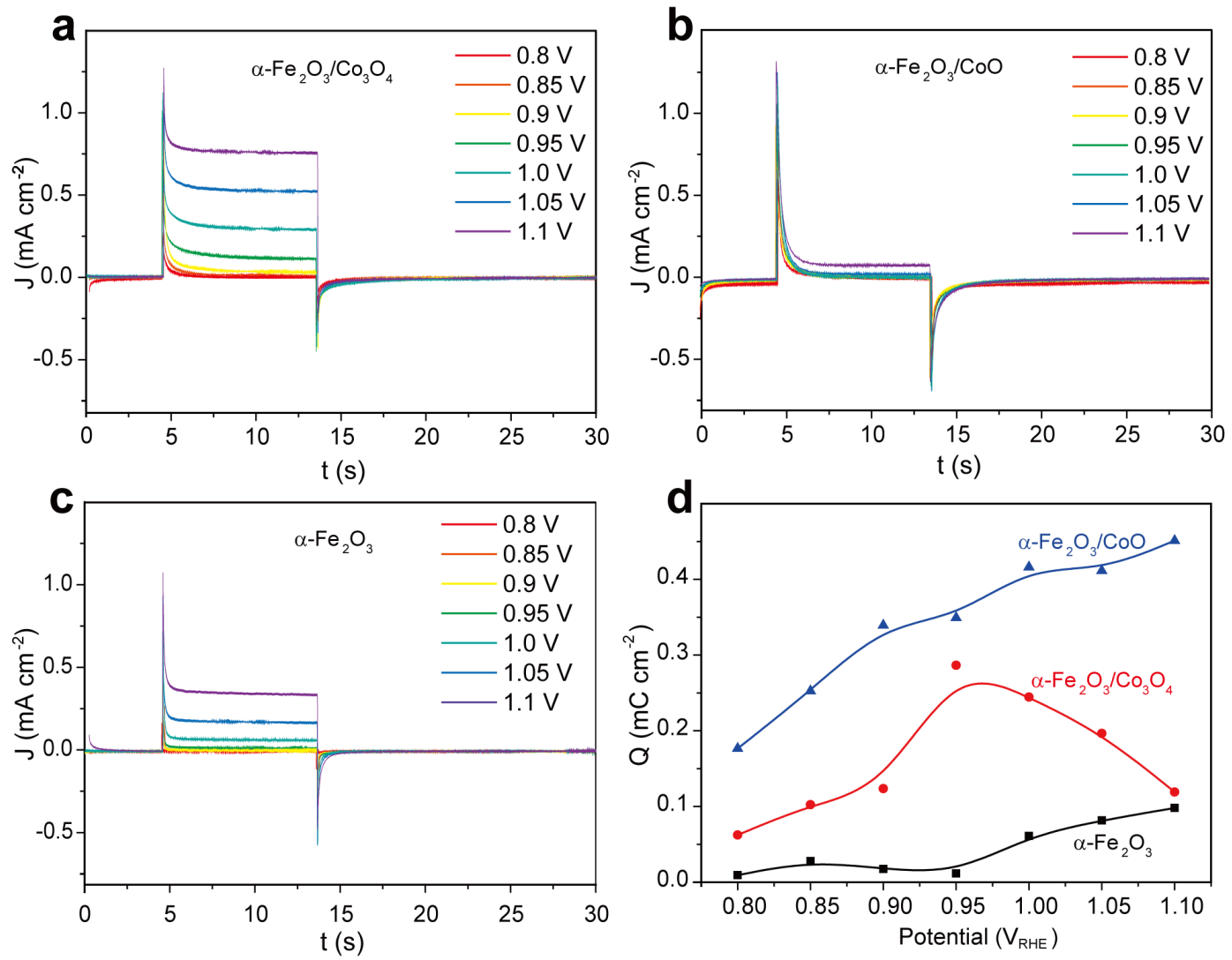

Figure S5. Chopped light chronoamperometry measurements of (a) $\alpha-\mathrm{Fe}_{2} \mathrm{O}_{3} / \mathrm{Co}_{3} \mathrm{O}_{4}$, (b) $\alpha$ $\mathrm{Fe}_{2} \mathrm{O}_{3} / \mathrm{CoO}$, and (c) $\alpha-\mathrm{Fe}_{2} \mathrm{O}_{3}$ at $0.8-1.1 \mathrm{~V}_{\mathrm{RHE}}$, (d) the hole accumulation density calculated by integrating the cathodic transient photocurrent region. 

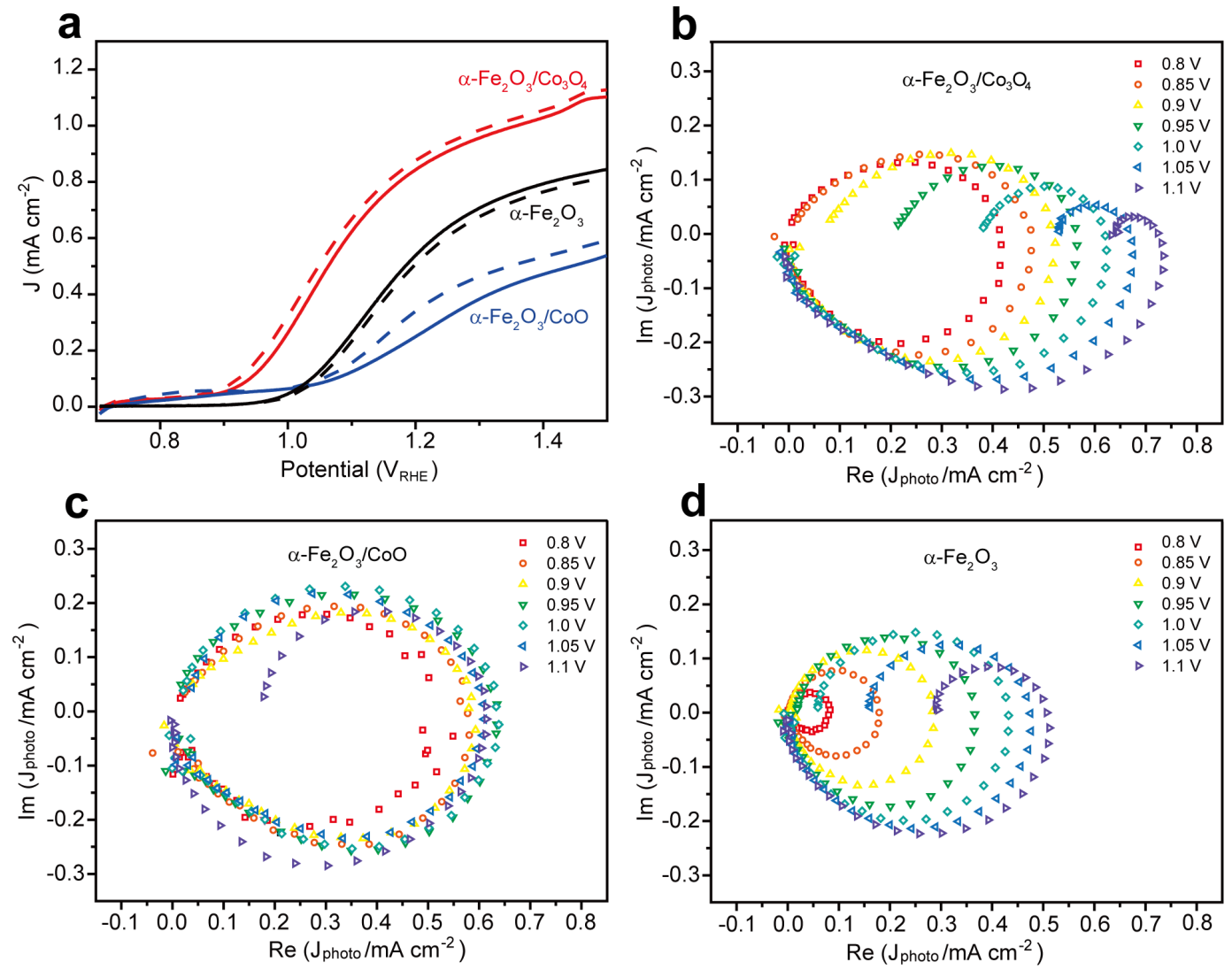

Figure S6. (a) J-V curves under $100 \mathrm{~mW} \mathrm{~cm}{ }^{-2}$ white LED before (solid lines) and after (dashed lines) the IMPS test. Full IMPS complex plots of (b) $\alpha-\mathrm{Fe}_{2} \mathrm{O}_{3} / \mathrm{Co}_{3} \mathrm{O}_{4}$, (c) $\alpha-\mathrm{Fe}_{2} \mathrm{O}_{3} / \mathrm{CoO}$, and (d) $\alpha$ $\mathrm{Fe}_{2} \mathrm{O}_{3}$ at $0.8-1.1 \mathrm{~V}_{\text {RHE. }}$. 

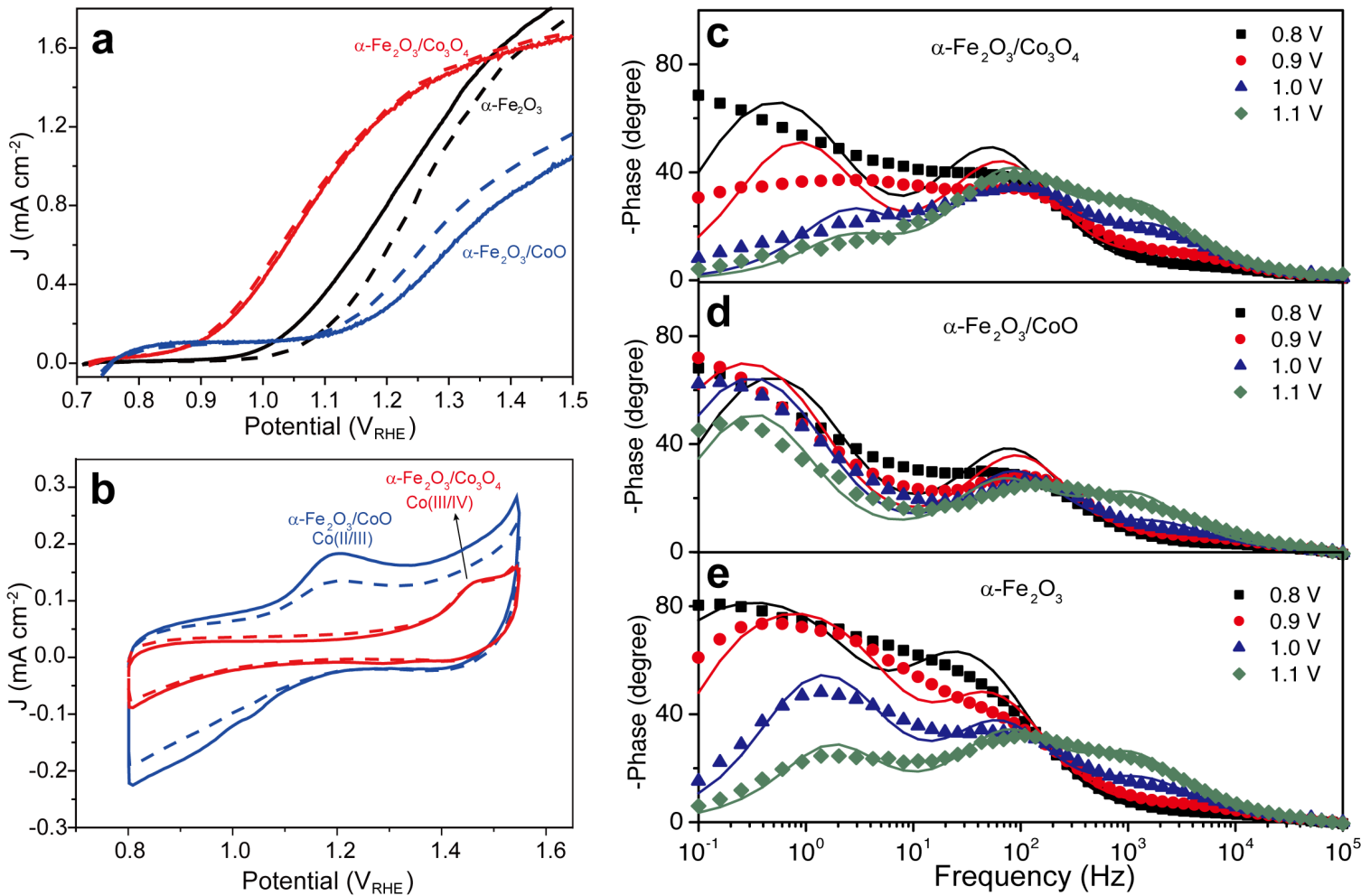

Figure S7. (a) $\mathrm{J}-\mathrm{V}$ curves under 1 sun irradiation of $\alpha-\mathrm{Fe}_{2} \mathrm{O}_{3} / \mathrm{Co}_{3} \mathrm{O}_{4}, \alpha-\mathrm{Fe}_{2} \mathrm{O}_{3} / \mathrm{CoO}$, and $\alpha-\mathrm{Fe}_{2} \mathrm{O}_{3}$,

(b) dark $\mathrm{CV}$ curves of $\alpha-\mathrm{Fe}_{2} \mathrm{O}_{3} / \mathrm{Co}_{3} \mathrm{O}_{4}$ and $\alpha-\mathrm{Fe}_{2} \mathrm{O}_{3} / \mathrm{CoO}$ before (solid lines) and after (dashed lines) the PEIS test. Bode plots (dotted lines) and the corresponding fitted (solid) lines for (c) $\alpha$ $\mathrm{Fe}_{2} \mathrm{O}_{3} / \mathrm{Co}_{3} \mathrm{O}_{4}$, (d) $\alpha-\mathrm{Fe}_{2} \mathrm{O}_{3} / \mathrm{CoO}$, and (e) $\alpha-\mathrm{Fe}_{2} \mathrm{O}_{3}$.

The equivalent circuit used to fit the PEIS data consists of a solution resistance $\left(\mathrm{R}_{\mathrm{S}}\right)$, a resistance $\left(\mathrm{R}_{\mathrm{FTO}}\right.$-bulk $)$ and a capacitance $\left(\mathrm{C}_{\text {FTO-bulk }}\right)$ in parallel to simulate the FTO- $\alpha-\mathrm{Fe}_{2} \mathrm{O}_{3}$ interface, a capacitance of bulk $\alpha-\mathrm{Fe}_{2} \mathrm{O}_{3}\left(\mathrm{C}_{\text {bulk }}\right)$, and the other capacitances and resistances $\left(\mathrm{R}_{\text {trap }}, \mathrm{R}_{\mathrm{ct}}, \mathrm{C}_{\text {surf }}\right.$ ) that have been explained in the main text. 

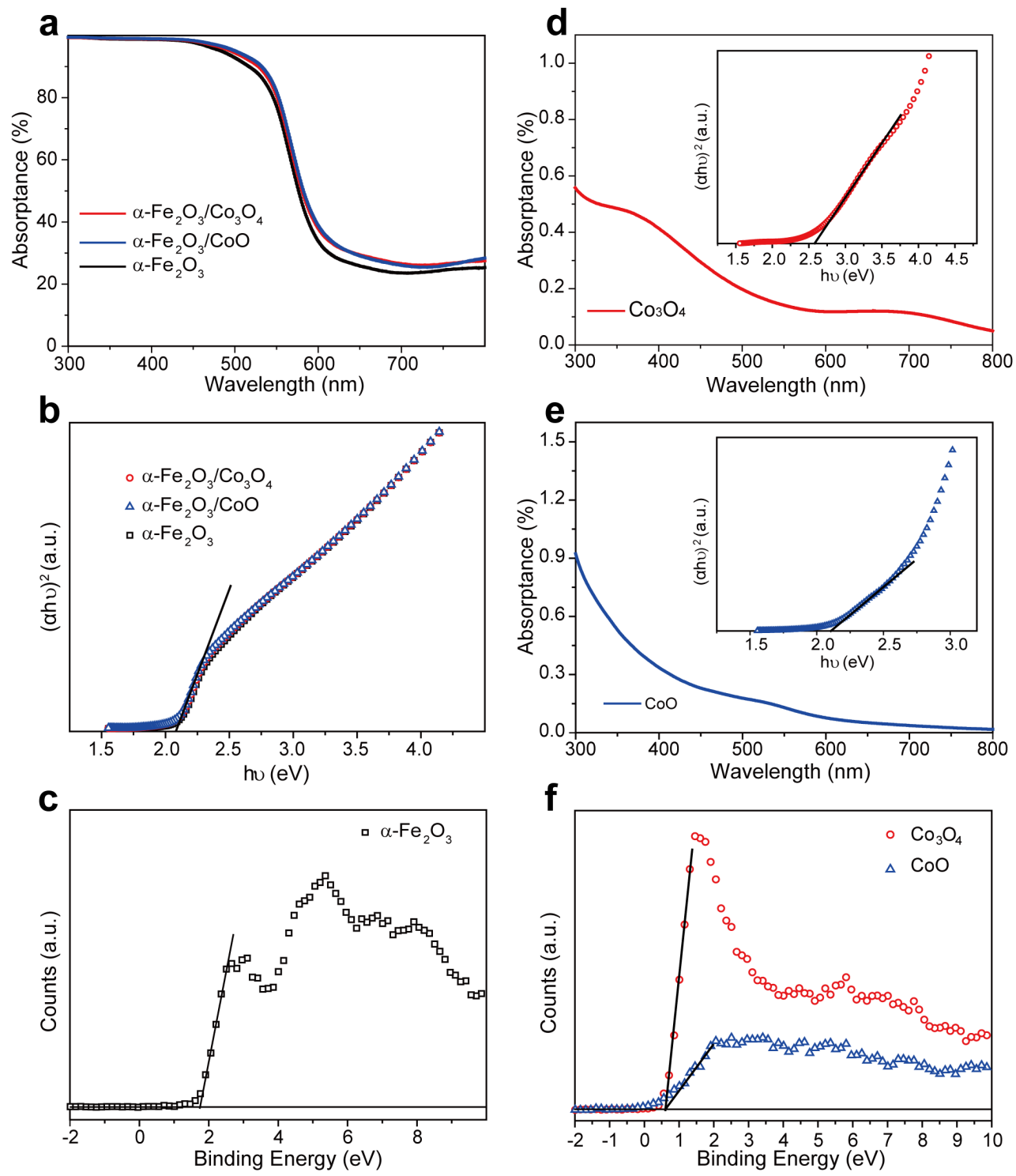

Figure S8. (a) UV-visible absorptance spectra and (b) the corresponding Tauc plots of $\alpha$ $\mathrm{Fe}_{2} \mathrm{O}_{3} / \mathrm{Co}_{3} \mathrm{O}_{4}, \alpha-\mathrm{Fe}_{2} \mathrm{O}_{3} / \mathrm{CoO}$, and $\alpha-\mathrm{Fe}_{2} \mathrm{O}_{3}$; (c) the valence band region of the XPS spectrum of $\alpha$ $\mathrm{Fe}_{2} \mathrm{O}_{3}$. (d) UV-visible absorptance spectra, (e) the corresponding Tauc plots, and (f) the valence band region of the XPS spectra of $\mathrm{Co}_{3} \mathrm{O}_{4}$ and $\mathrm{CoO}$.

The conductivity types of $\alpha-\mathrm{Fe}_{2} \mathrm{O}_{3}, \mathrm{Co}_{3} \mathrm{O}_{4}$, and $\mathrm{CoO}$ were confirmed by combining the bandgap measurements with the XPS spectra. All $\alpha-\mathrm{Fe}_{2} \mathrm{O}_{3}$ films with and without EC coating have a bandgap value of $2.1 \mathrm{eV}$ as indicated by the UV-visible absorptance spectra (Figure S8a) and the corresponding Tauc plots (Figure S8b). The valence band region of the XPS spectrum of $\alpha-\mathrm{Fe}_{2} \mathrm{O}_{3}$ (Figure $\mathrm{S} 8 \mathrm{c})$ shows that the distance between the position of valence band $\left(\mathrm{E}_{\mathrm{VB}}\right)$ and the Fermi level $\left(\mathrm{E}_{\mathrm{F}}\right)$ is $1.7 \mathrm{eV}$, and thus the distance between $\mathrm{E}_{\mathrm{F}}$ and the position of the conduction band $\left(\mathrm{E}_{\mathrm{CB}}\right)$ is $0.4 \mathrm{eV}$. Therefore, the closer $\mathrm{E}_{\mathrm{F}}-\mathrm{E}_{\mathrm{CB}}$ distance than the $\mathrm{E}_{\mathrm{VB}}-\mathrm{E}_{\mathrm{F}}$ distance indicates the n-type conductivity of $\alpha-\mathrm{Fe}_{2} \mathrm{O}_{3}$. Bandgap val- 
ues of $2.6 \mathrm{eV}$ for $\mathrm{Co}_{3} \mathrm{O}_{4}$ and $2.1 \mathrm{eV}$ for $\mathrm{CoO}$ are obtained from their UV-visible absorptance spectra (Figure S8d) and the corresponding Tauc plots (Figure S8e). The valence band region of the XPS spectra (Figure S8f) shows that the $E_{V B}-E_{F}$ distance is $0.6 \mathrm{eV}$ for both $\mathrm{Co}_{3} \mathrm{O}_{4}$ and $\mathrm{CoO}$, and thus the $\mathrm{E}_{\mathrm{F}}-\mathrm{E}_{\mathrm{CB}}$ distances are $2.0 \mathrm{eV}$ for $\mathrm{Co}_{3} \mathrm{O}_{4}$ and $1.5 \mathrm{eV}$ for $\mathrm{CoO}$. Therefore, the closer $\mathrm{E}_{\mathrm{VB}}-\mathrm{E}_{\mathrm{F}}$ distance than the $\mathrm{E}_{\mathrm{F}}-\mathrm{E}_{\mathrm{CB}}$ distance indicates that both $\mathrm{Co}_{3} \mathrm{O}_{4}$ and $\mathrm{CoO}$ are p-type semiconductors. ${ }^{6}$ The above conductivity type analysis indicates that both ECs can form $\mathrm{p}-\mathrm{n}$ junctions with $\alpha-\mathrm{Fe}_{2} \mathrm{O}_{3}$. 

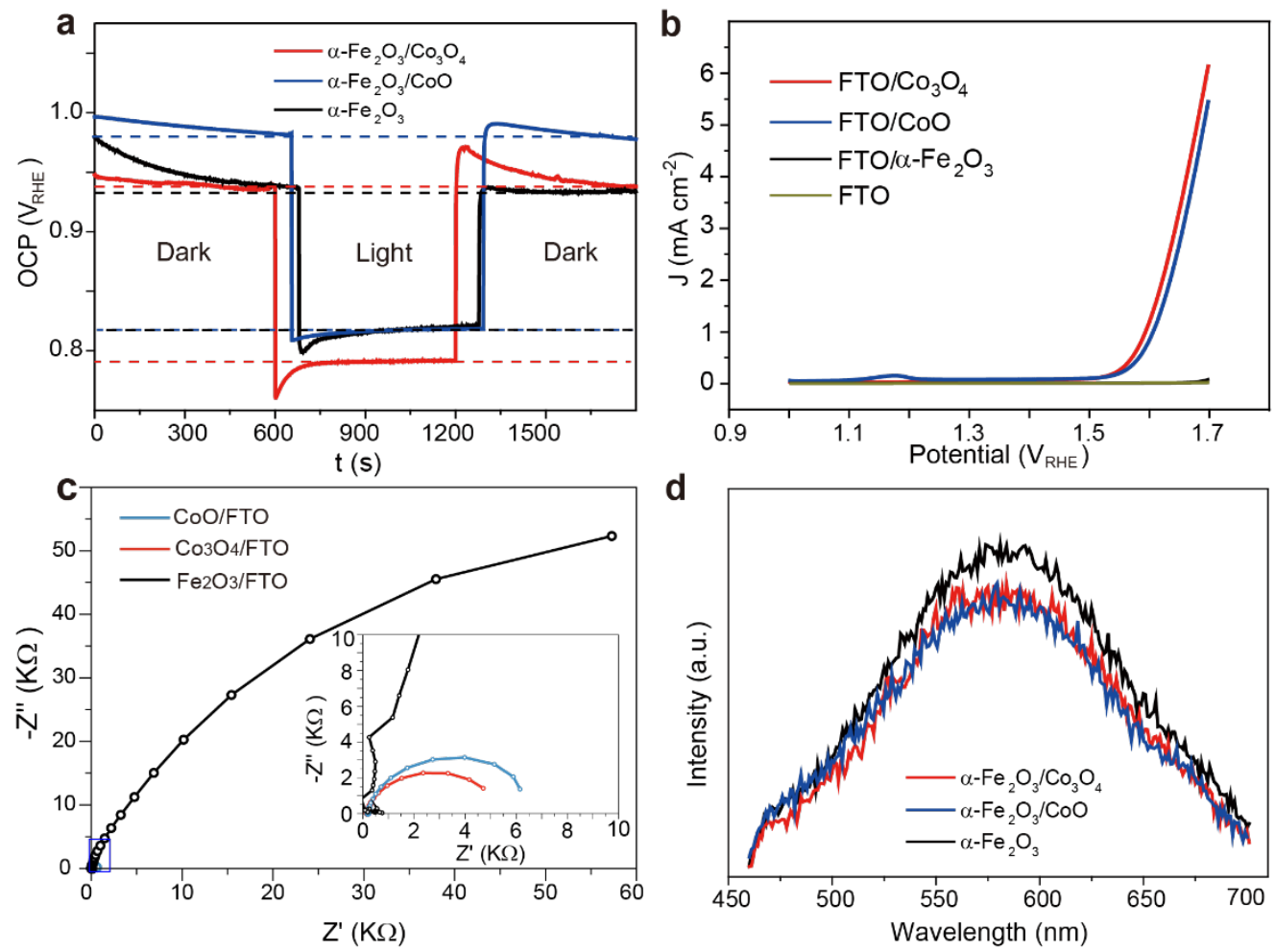

Figure S9. (a) OCP measurements of $\alpha-\mathrm{Fe}_{2} \mathrm{O}_{3} / \mathrm{Co}_{3} \mathrm{O}_{4}, \alpha-\mathrm{Fe}_{2} \mathrm{O}_{3} / \mathrm{CoO}$, and $\alpha-\mathrm{Fe}_{2} \mathrm{O}_{3}$. (b) Dark J-V curves of $\mathrm{Co}_{3} \mathrm{O}_{4} / \mathrm{FTO}, \mathrm{CoO} / \mathrm{FTO}, \alpha-\mathrm{Fe}_{2} \mathrm{O}_{3} / \mathrm{FTO}$, and the bare FTO. (c) EIS Nyquist plots of $\mathrm{Co} 3 \mathrm{O} 4 / \mathrm{FTO}, \mathrm{CoO} / \mathrm{FTO}$, and $\mathrm{a}-\mathrm{Fe}_{2} \mathrm{O}_{3} / \mathrm{FTO}$ measured at $1.57 \mathrm{~V}$ RHE. Inset is the zoom-in view of the blue rectangle zone. (d) Photoluminescence emission spectra of $\alpha-\mathrm{Fe}_{2} \mathrm{O}_{3} / \mathrm{Co}_{3} \mathrm{O}_{4}, \alpha-\mathrm{Fe}_{2} \mathrm{O}_{3} / \mathrm{CoO}$ and $\alpha-\mathrm{Fe}_{2} \mathrm{O}_{3}$.

The open-circuit potentials (OCPs) of all three photoanodes were measured (Figure S9a), and the difference between the OCPs measured in the dark and under illumination of a photoanode is regarded as the photovoltage. The photovoltage of $\alpha-\mathrm{Fe}_{2} \mathrm{O}_{3}(114 \mathrm{mV})$ increases after coating the ECs $(147 \mathrm{mV}$ for $\alpha$ $\mathrm{Fe}_{2} \mathrm{O}_{3} / \mathrm{Co}_{3} \mathrm{O}_{4}$ and $160 \mathrm{mV}$ for $\alpha-\mathrm{Fe}_{2} \mathrm{O}_{3} / \mathrm{CoO}$ ). The increased photovoltages of the EC-coated photoanodes compared to that of the bare one (Figure S9a) can be attributed to the passivation of surface states, or the formation of $p-n$ junctions between $\alpha-\mathrm{Fe}_{2} \mathrm{O}_{3}$ and the ECs as inferred from the conductivity type analysis (Figure S8a-S8f). Figure S9b shows that the overpotentials at $1 \mathrm{~mA} \mathrm{~cm}^{-2}$ for $\mathrm{Co}_{3} \mathrm{O}_{4}$ and $\mathrm{CoO}$ are 360 and $370 \mathrm{mV}$, respectively, and the small difference indicates that the two ECs are similarly active for the OER. Furthermore, only one semi-circle arc corresponding to the EC-electrolyte interfacial charge transfer resistance is shown for both electrodes as well as bare hematite (Figure S9c). Only one semi-circle arc corresponding to the EC-electrolyte interfacial charge transfer resistance is shown for both electrodes as well as bare hematite. Both 
ECs possess significantly smaller arc than bare hematite, indicating their excellent electrocatalytic OER activity in comparison with bare hematite. Moreover, in accordance with the potential sweep curves in Figure $\mathrm{S} 9 \mathrm{~b}$, the $\mathrm{Co}_{3} \mathrm{O}_{4} / \mathrm{FTO}$ electrode also shows a similar arc with the CoO/FTO, revealing their similar reaction kinetics for OER. Therefore, the electrocatalytic OER activities of $\mathrm{CoO}$ and $\mathrm{Co}_{3} \mathrm{O}_{4}$ is also not the determinant reason for the PEC OER activity difference. 

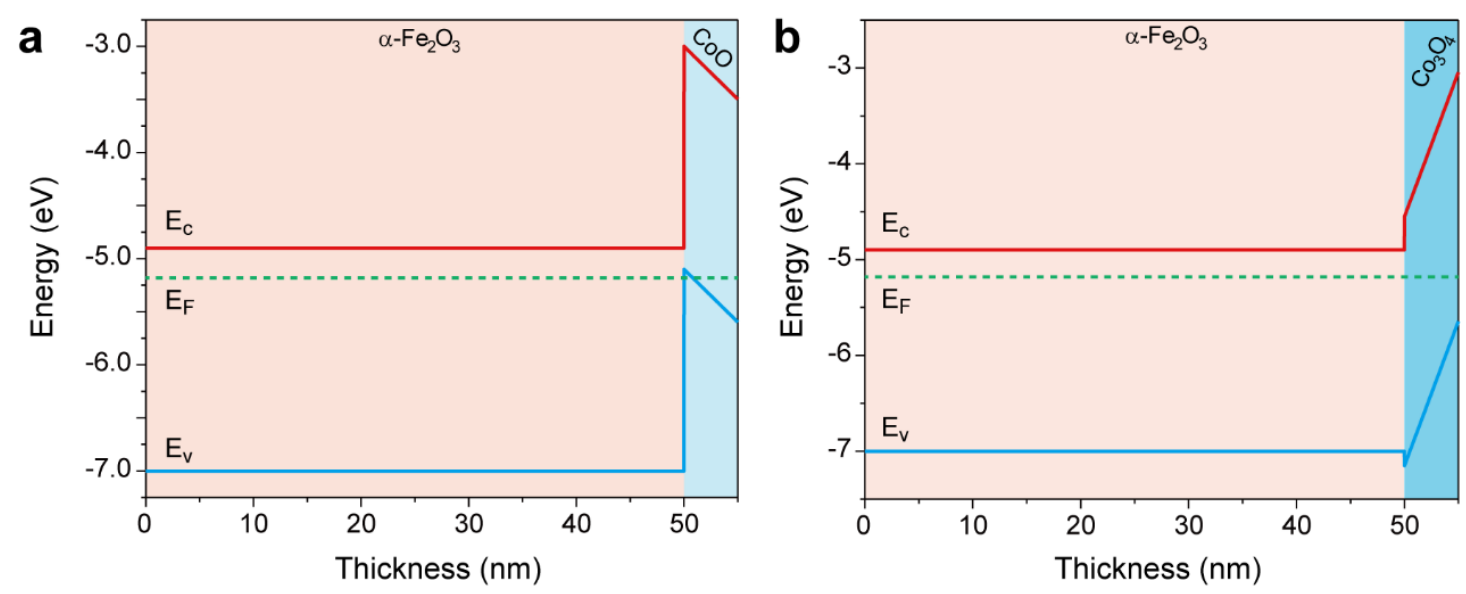

Figure S10. Simulated band diagrams of the (a) $\alpha-\mathrm{Fe}_{2} \mathrm{O}_{3} / \mathrm{CoO}$ and (b) $\alpha-\mathrm{Fe}_{2} \mathrm{O}_{3} / \mathrm{Co}_{3} \mathrm{O}_{4}$ heterojunctions using the AFORS-HET program. $\mathrm{E}_{\mathrm{c}}, \mathrm{E}_{\mathrm{v}}$, and $\mathrm{E}_{\mathrm{F}}$ represent for conduction band minimum, valence band maximum, and Fermi level, respectively.

Figure S10 shows the simulated band diagrams of the $\alpha-\mathrm{Fe}_{2} \mathrm{O}_{3} / \mathrm{Co}_{3} \mathrm{O}_{4}$ and $\alpha$ $\mathrm{Fe}_{2} \mathrm{O}_{3} / \mathrm{CoO}$ heterojunctions using the AFORS-HET program ${ }^{7}$ based on the parameters in Table S1. As can be seen from Figure S10, there is no significant band bending observed at the interface of both heterojunctions, in which the band tilt in $\mathrm{CoO}$ and $\mathrm{Co}_{3} \mathrm{O}_{4}$ may be due to their small size that cannot be correctly handled by this program.

Table S1. Parameters and the corresponding values used in the simulation by the AFORSHET program.

\begin{tabular}{lccc}
\hline Material & $\alpha-\mathrm{Fe}_{2} \mathrm{O}_{3}$ & $\mathrm{CoO}$ & $\mathrm{Co}_{3} \mathrm{O}_{4}$ \\
\hline Film thickness $(\mathrm{nm})$ & 50 & 5 & 5 \\
dielectric constant-dk & $80^{8}$ & $12.9^{9}$ & $13^{10}$ \\
Electron affinity-chi $(\mathrm{eV})$ & $4.9^{11}$ & $3^{12}$ & $4.55^{10}$ \\
Band gap-Eg $(\mathrm{eV})$ & 2.1 & 2.1 & 2.6 \\
Effective conduction band density- $\mathrm{N}_{\mathrm{c}}\left(\mathrm{cm}^{-3}\right)$ & $5.3 \mathrm{E} 20^{13}$ & $1 \mathrm{E} 19$ & $8.9 \mathrm{E} 19^{14}$ \\
Effective valence band density- $\mathrm{N}_{\mathrm{v}}\left(\mathrm{cm}^{-3}\right)$ & $2 \mathrm{E} 19^{13}$ & $1 \mathrm{E} 19$ & $6.3 \mathrm{E} 19^{14}$ \\
Effective electron mobility- $\mu_{\mathrm{n}}\left(\mathrm{cm}^{-2} \mathrm{~V}^{-1} \mathrm{~S}^{-1}\right)$ & $4.5^{13}$ & $0.3^{15}$ & $1^{16}$ \\
Effective hole mobility- $\mu_{\mathrm{p}}\left(\mathrm{cm}^{-2} \mathrm{~V}^{-1} \mathrm{~S}^{-1}\right)$ & $1.5^{13}$ & $0.3^{15}$ & $1^{16}$ \\
Doping concentration acceptors- $\mathrm{N}_{\mathrm{a}}\left(\mathrm{cm}^{-3}\right)$ & 0 & $1 \mathrm{E} 12$ & $1 \mathrm{E} 12$ \\
Doping concentration donors- $\mathrm{N}_{\mathrm{d}}\left(\mathrm{cm}^{-3}\right)$ & $1 \mathrm{E} 16$ & 0 & 0 \\
\hline
\end{tabular}



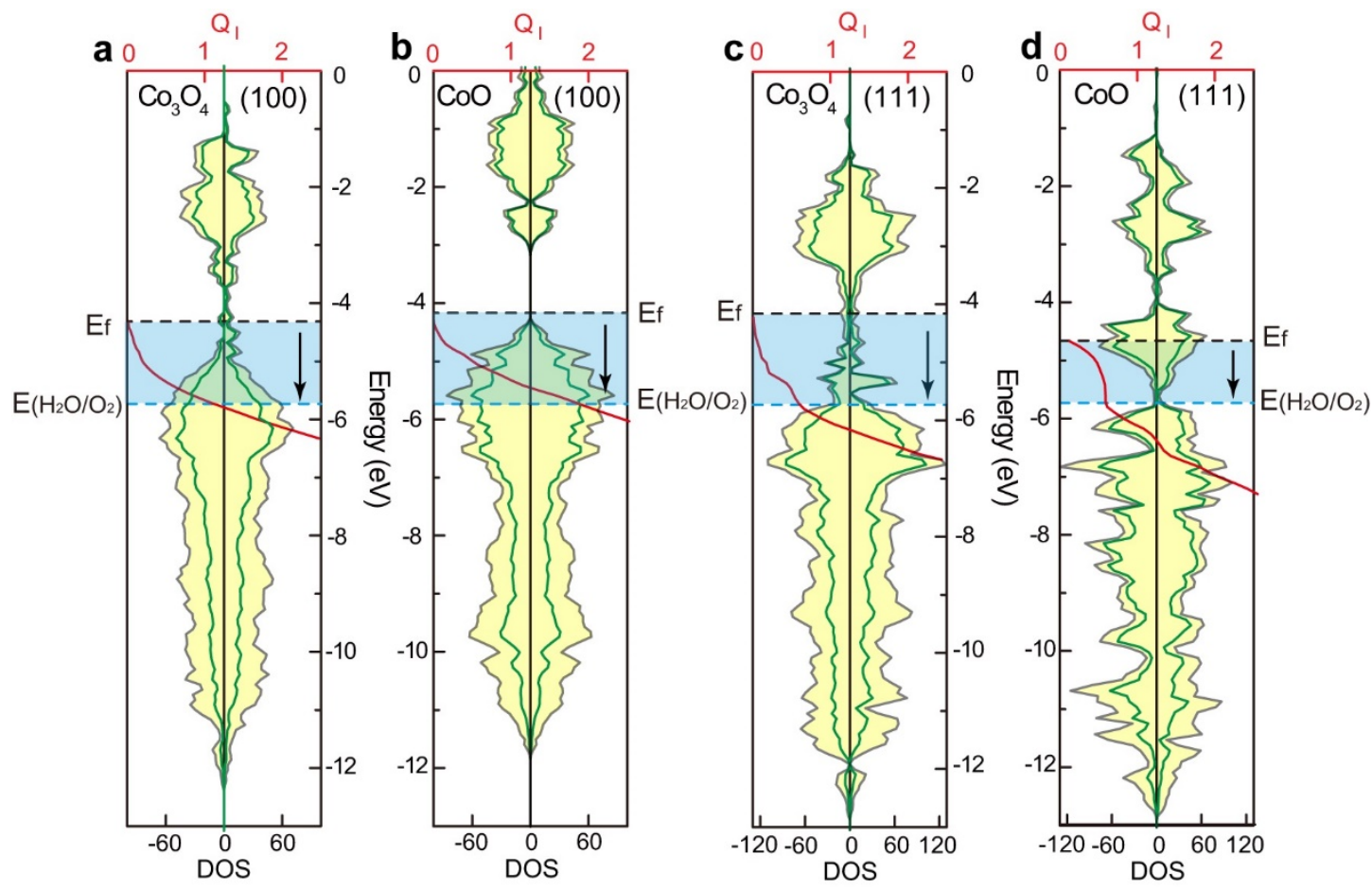

Figure S11. DFT calculation results of (a) $\mathrm{Co}_{3} \mathrm{O}_{4}$ (100), (b) $\mathrm{CoO}$ (100), (c) $\mathrm{Co}_{3} \mathrm{O}_{4}$ (111), and (d) $\mathrm{CoO}$ (111) facets. The total DOS (grey lines) and the PDOS of Co $d$-orbitals (green lines) are referenced to the vacuum level. The red lines indicate the integral PDOS of Co $d$ orbitals from the Fermi levels $\left(E_{f}\right)$. The light blue regions from the $E_{f}$ to the OER potential indicate the PDOS integration ranges to determine the hole storage capacity.

Table S2. The number of Co atoms, Fermi level, and Q for the $\mathrm{Co}_{3} \mathrm{O}_{4}$ and $\mathrm{CoO}$ models with diffrent facets.

\begin{tabular}{ccccccc}
\hline & \multicolumn{3}{c}{$\mathrm{Co}_{3} \mathrm{O}_{4}$} & \multicolumn{3}{c}{$\mathrm{CoO}$} \\
\cline { 2 - 7 } & $\begin{array}{c}\text { Number of Co } \\
\text { atoms in model }\end{array}$ & $\begin{array}{c}\text { Fermi level } \\
(\mathrm{eV})\end{array}$ & $\mathrm{Q}_{1}$ & $\begin{array}{c}\text { Number of Co } \\
\text { atoms in model }\end{array}$ & $\begin{array}{c}\text { Fermi level } \\
(\mathrm{eV})\end{array}$ & $\mathrm{Q}_{1}$ \\
\hline$(110)$ & 44 & -5.12 & 0.4 & 48 & -3.95 & 1.2 \\
$(100)$ & 38 & -4.31 & 1.1 & 48 & -4.17 & 1.9 \\
$(111)$ & 60 & -4.17 & 0.6 & 64 & -4.66 & 0.6 \\
\hline
\end{tabular}

The averaged $\mathrm{Q}_{1}$ values of (110), (100), and (111) facets are 0.7 for $\mathrm{Co}_{3} \mathrm{O}_{4}$ and 1.2 for $\mathrm{CoO}$, suggesting the larger hole storage capacity of $\mathrm{CoO}$ than that of $\mathrm{Co}_{3} \mathrm{O}_{4}$, which is consistent with the experimental measurements. It is also worth noticing that the reported work functions for bulk $\mathrm{Co}_{3} \mathrm{O}_{4}$ and bulk $\mathrm{CoO}$ by experimental measurements ${ }^{17}$ are $6.3 \pm 0.3$ and $4.6 \pm 0.2 \mathrm{eV}$, respectively, indicating that bulk $\mathrm{CoO}$ also has a higher Fermi level than bulk $\mathrm{Co}_{3} \mathrm{O}_{4}$. That is, 
the integration value between the projected DOS of Co $d$-orbitals from the Fermi level to the OER potential for bulk $\mathrm{CoO}$ could be also larger than that for bulk $\mathrm{Co}_{3} \mathrm{O}_{4}$, which is consistent with our calculation result obtained from the typical facets of $\mathrm{Co}_{3} \mathrm{O}_{4}$ and $\mathrm{CoO}$. 


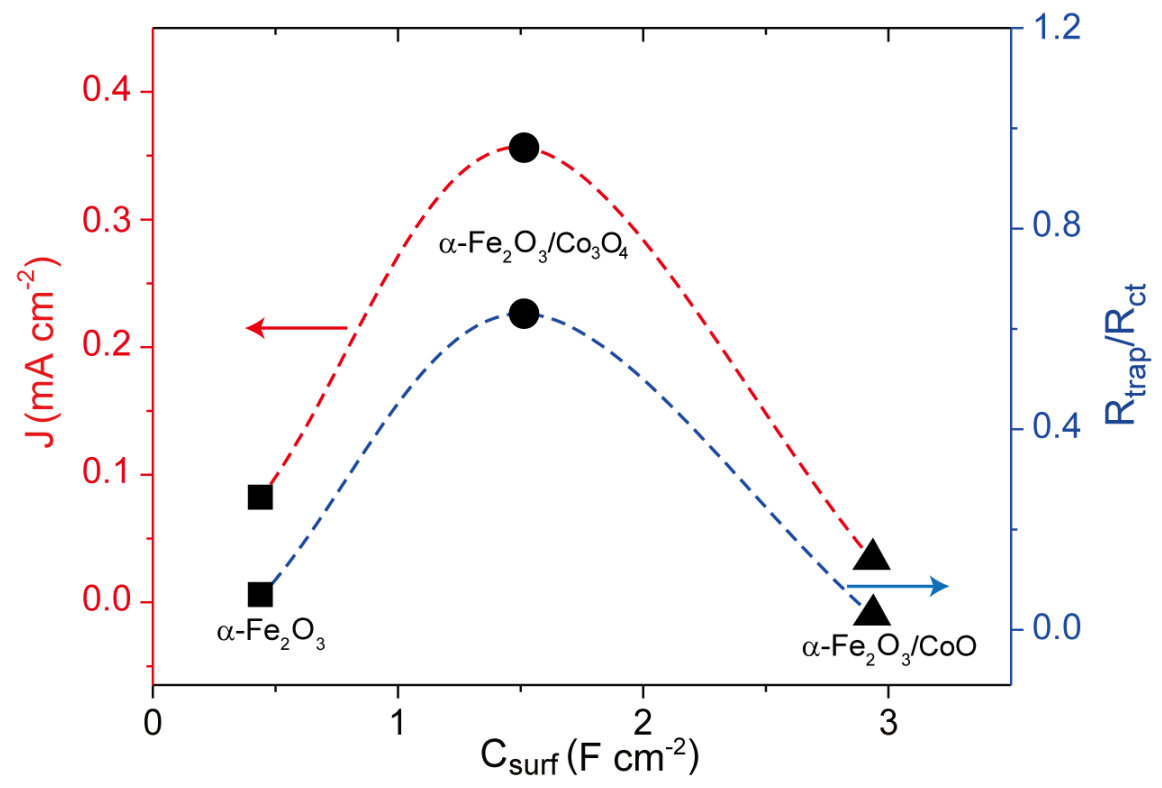

Figure S12. Photocurrent densities and $\mathrm{R}_{\text {trap }} / \mathrm{R}_{\mathrm{ct}}$ values as a function surface capacitances.

Summarized from $\alpha-\mathrm{Fe}_{2} \mathrm{O}_{3} / \mathrm{Co}_{3} \mathrm{O}_{4}, \alpha-\mathrm{Fe}_{2} \mathrm{O}_{3} / \mathrm{CoO}$, and $\alpha-\mathrm{Fe}_{2} \mathrm{O}_{3}$ measured at $1.0 \mathrm{~V}$ RHE. Dashed lines are guides to the eye.

The inverted-U-shaped $\mathrm{J}-\mathrm{C}_{\text {surf }}$ curve (red line) shows that the PEC OER activity changes non-monotonically with increasing surface hole density. The $R_{\text {trap }} / R_{c^{-}}$ $\mathrm{C}_{\text {surf }}$ curve (blue line) also exhibits a consistent inverted-U shape, further revealing that the competition between interfacial charge transfer and recombination determines the photocurrent density, which is controlled by the surface hole density.

\section{References}

1. Rivas-Murias, B.; Salgueiriño, V., Thermodynamic $\mathrm{CoO}-\mathrm{Co}_{3} \mathrm{O}_{4}$ Crossover Using Raman Spectroscopy in Magnetic Octahedron-Shaped Nanocrystals. J. Raman Spectrosc. 2017, 48, 837-841.

2. Yuan, X.; Ge, H.; Wang, X.; Dong, C.; Dong, W.; Riaz, M. S.; Xu, Z.; Zhang, J.; Huang, F., Controlled Phase Evolution from Co Nanochains to CoO Nanocubes and Their Application as Oer Catalysts. ACS Energy Lett. 2017, 2, 1208-1213.

3. Guan, J.; Ding, C.; Chen, R.; Huang, B.; Zhang, X.; Fan, F.; Zhang, F.; Li, C., $\mathrm{CoO}_{\mathrm{x}}$ Nanoparticle Anchored on Sulfonated-Graphite as Efficient Water Oxidation Catalyst. Chem. Sci. 2017, 8, 6111-6116.

4. Favaro, M.; Yang, J.; Nappini, S.; Magnano, E.; Toma, F. M.; Crumlin, E. J.; Yano, J.; Sharp, I. D., Understanding the Oxygen Evolution Reaction Mechanism on $\mathrm{CoO}_{\mathrm{x}}$ Using Operando Ambient-Pressure X-Ray Photoelectron Spectroscopy. J. Am. Chem. Soc. 2017, 
139, 8960-8970.

5. Qiu, J.; Hajibabaei, H.; Nellist, M. R.; Laskowski, F. A.; Hamann, T. W.; Boettcher, S. W., Direct in Situ Measurement of Charge Transfer Processes During Photoelectrochemical Water Oxidation on Catalyzed Hematite. ACS Central Sci. 2017, 3, 1015-1025.

6. Xu, Y. F.; Wang, X. D.; Chen, H. Y.; Kuang, D. B.; Su, C. Y., Toward High Performance Photoelectrochemical Water Oxidation: Combined Effects of Ultrafine Cobalt Iron Oxide Nanoparticle. Adv. Func. Mater. 2016, 26, 4414-4421.

7. Varache, R.; Leendertz, C.; Gueunier-Farret, M. E.; Haschke, J.; Muñoz, D.; Korte, L., Investigation of Selective Junctions Using a Newly Developed Tunnel Current Model for Solar Cell Applications. Sol. Energy Mater. So. Cells 2015, 141, 14-23.

8. Zhang, K.; Dong, T.; Xie, G.; Guan, L.; Guo, B.; Xiang, Q.; Dai, Y.; Tian, L.; Batool, A.; Jan, S. U., Sacrificial Interlayer for Promoting Charge Transport in Hematite Photoanode. ACS Appl. Mater. Interfaces 2017, 9, 42723-42733.

9. Rao, K. V.; Smakula, A., Dielectric Properties of Cobalt Oxide, Nickel Oxide, and Their Mixed Crystals. J. Appl. Phys. 1965, 36, 2031-2038.

10. Herner, S. B.; Weerakkody, A. D.; Belkadi, A.; Moddel, G., High Performance Miim Diode Based on Cobalt Oxide/Titanium Oxide. Appl. Phys. Lett. 2017, 110, 1-34.

11. Lohaus, C.; Klein, A.; Jaegermann, W., Limitation of Fermi Level Shifts by Polaron Defect States in Hematite Photoelectrodes. Nat. Commun. 2018, 9, 4309.

12. Thorpe, R.; Rangan, S.; Sina, M.; Cosandey, F.; Bartynski, R. A., Conversion Reaction of CoO Polycrystalline Thin Films Exposed to Atomic Lithium. J. Phys. Chem. C 2013, 117, 14518-14525.

13. Li, C.; Wu, S.; Dong, M.; Shang, A.; Li, X., Optoelectronic Modeling of the $\mathrm{Si} / \alpha-\mathrm{Fe}_{2} \mathrm{O}_{3}$ Heterojunction Photoanode. Nano Energy 2017, 43, 177-183.

14. Blakemore, J. D.; Gray, H. B.; Winkler, J. R.; Müller, A. M., $\mathrm{Co}_{3} \mathrm{O}_{4}$ Nanoparticle WaterOxidation Catalysts Made by Pulsed-Laser Ablation in Liquids. ACS Catal. 2013, 3, 24972500.

15. Daal, H.; Bosman, A., Hall Effect in $\mathrm{CoO}, \mathrm{NiO}$, and $\alpha-\mathrm{Fe}_{2} \mathrm{O}_{3}$. Phys. Rev. 1967, 158, 736747.

16. Varghese, B.; Mukherjee, B.; Karthik, K. R. G.; Jinesh, K. B.; Sow, C. H., Electrical and Photoresponse Properties of $\mathrm{Co}_{3} \mathrm{O}_{4}$ Nanowires. J. Appl. Phys. 2012, 111, 828-839.

17. Greiner, M. T.; Lu, Z.-H., Thin-Film Metal Oxides in Organic Semiconductor Devices: Their Electronic Structures, Work Functions and Interfaces. NPG Asia Mater. 2013, 5, e55. 